\title{
Novel mutations of the calcium-sensing receptor impede differential diagnosis of primary hyperparathyroidism and familial hypocalciuric hypercalcemia
}

\author{
Jagdeep Singh Bhangu ${ }^{1}$, Sabina Baumgartner-Parzer ${ }^{2}$, Lindsay Hargitai ${ }^{1}$, Peter Mazal ${ }^{3}$, \\ Christian Scheuba ${ }^{1}$, Philipp Riss ${ }^{1}$
}

${ }^{1}$ Division of Visceral Surgery, Department of General Surgery, Medical University of Vienna, Vienna, Austria; ${ }^{2}$ Division of Endocrinology and Metabolism, Department of Internal Medicine III, Medical University of Vienna, Vienna, Austria; ${ }^{3}$ Division of Clinical Pathology, Department of Pathology, Medical University of Vienna, Vienna, Austria

Contributions: (I) Conception and design: P Riss, JS Bhangu; (II) Administrative support: P Riss, C Scheuba; (III) Provision of study materials or patients: P Riss, C Scheuba, P Mazal; (IV) Collection and assembly of data: JS Bhangu, L Hargitai; (V) Data analysis and interpretation: JS Bhangu, P Riss, S Baumgartner-Parzer; (VI) Manuscript writing: All authors; (VII) Final approval of manuscript: All authors.

Correspondence to: Dr. Jagdeep Singh Bhangu, MD, PhD. Division of Visceral Surgery, Department of General Surgery, Medical University of Vienna, Waehringer Guertel 18-20, Vienna A-1090, Austria. Email: JagdeepSingh.Bhangu@gesundheitsverbund.at.

Background: Familial hypocalciuric hypercalcemia 1 (FHH1) is an autosomal dominant disorder caused by inactivating mutations in the calcium-sensing receptor (CaSR) gene, commonly leading-in contrast to primary hyperparathyroidism (PHPT) — to asymptomatic hypercalcemia. It is important to establish the correct diagnosis, as surgery may be curative in PHPT, but most likely ineffective in FHH. The study aims to evaluate patients with FHH1, initially misinterpreted as PHPT and some even undergone surgery.

Methods: CaSR-genotyping was conducted, various biochemical parameters including twenty-four-hour urinary $\mathrm{Ca}$ excretion (24hU CE) and the calculated relation of urinary Ca clearance to creatinine clearance (CCCR), type of surgery and 1-year follow-up data of fourteen patients with proven FHH1 were evaluated retrospectively.

Results: Genetic analysis revealed a total of nine novel heterozygous variants in the CaSR gene in our study population. Six of fourteen patients (42.9\%) underwent surgery for initially suspected PHPT, showing normalized biochemical parameters immediately after surgery. In 1-year follow-up, however, five of six operated patients $(83.3 \%)$ showed normal parathyroid hormone (PTH), but elevated serum calcium levels. In contrast, only one of the operated patients (16.7\%) presented both PTH and serum calcium in the normal range. Histology showed adenoma in three (50\%), hyperplasia in two $(33.3 \%)$, and normal parathyroid tissue in one $(16.7 \%)$ of the patients.

Conclusions: We discovered novel heterozygous variants in the CaSR gene, which considerably impede differential diagnosis of PHPT and FHH1. Furthermore, our results indicate that parathyroid surgery fails to provide long-term benefits for patients with FHH1 and suspected PHPT, even though this coincidence seems to exist.

Keywords: Primary hyperparathyroidism (PHPT); familial hypocalciuric hypercalcemia (FHH); parathyroid surgery; calcium-sensing receptor (CaSR)

Submitted Aug 24, 2021. Accepted for publication Nov 16, 2021.

doi: 10.21037 /gs-21-577

View this article at: https://dx.doi.org/10.21037/gs-21-577 


\section{Introduction}

Familial hypocalciuric hypercalcemia $(\mathrm{FHH})$ is a rare condition, characterized by elevated serum calcium (Ca) and inappropriately normal or slightly elevated parathyroid hormone (PTH) levels. The biochemical picture resembles that of primary hyperparathyroidism (PHPT) which seems to occur more frequently. FHH is usually diagnosed with family history and laboratory findings, especially lower urinary excretion of $\mathrm{Ca}(\mathrm{CE})$. Twenty-four-hour urinary (24hU) CE and the calculated relation of urinary $\mathrm{Ca}$ clearance to creatinine clearance (CCCR) are internationally recommended and thus widely used diagnostic tools to discriminate FHH from PHPT $(1,2)$. The distinction between the two diseases is very important, as prognosis and treatment differ distinctively $(3,4)$. Characteristically, FHH patients fail to respond to parathyroid surgery, in contrast to patients with PHPT who mostly benefit from such an intervention.

To date, three subtypes of FHH (FHH1 to 3) are known. The most common and best investigated form is FHH1 [Online Mendelian Inheritance in Man (OMIM): 145980], caused by heterozygous inactivating mutations of the Casensing receptor $(\mathrm{CaSR})$ gene located on chromosome 3 q21.1. The other two very rare subtypes FHH2 (OMIM: 145981) and FHH3 (OMIM: 600740) are caused by pathogenic variants of the guanine nucleotide-binding protein (G protein) alpha 11 (GNA11) and adaptor-related protein complex 2 sigma 1 subunit (AP2S1) genes, both located on chromosome 19.

The CaSR is a G protein-coupled membrane receptor expressed abundantly in tissues such as the parathyroid gland and kidney tubules (5). It operates by sensing small changes in circulating $\mathrm{Ca}$ concentrations in serum and, if activated, by inhibiting PTH secretion and renal-tubule $\mathrm{Ca}$ reabsorption $(3,6,7)$. Interestingly, CaSR is also expressed in myocardium, in enteric and pancreatic endocrine cells, adipose tissue as well as in many other tissues. Whereas recent data hint to a tissue-specific role of the CaSR concerning proliferation, differentiation and signaling at the molecular level $(8,9)$, patients with heterozygous CaSR germ line mutations were shown not to exhibit alterations in myocardial function, lipid distribution, or glucose metabolism (10).

Up to now, several hundred pathogenic variants of the CaSR gene have been published. With the objective of better understanding the variants that cause defects in the $C a S R$ gene and respective receptor functions, data on pathogenic variants are currently being collected in the Calcium-Sensing Receptor Database.

The aim of the present study was to analyze patients with FHH1, who were initially referred for PHPT by the endocrinologist or the general practitioner (GP). Some of these patients were misinterpreted for PHPT and subsequently underwent surgery. For this purpose, we retrospectively performed CaSR genotyping, analyzed various biochemical parameters, types of surgery and 1-year follow-up data of patients with proven FHH1.

We present the following article in accordance with the MDAR reporting checklist (available at https:// gs.amegroups.com/article/view/10.21037/gs-21-577/rc).

\section{Methods}

All patients were initially referred for PHPT by the endocrinologist or the GP. For quality assurance reasons, a mandatory re-checkup (biochemical analysis including CCCR and CE assessment) was conducted at patients' first consultation. Interestingly, after reviewing the results, the majority of patients was assumed for $\mathrm{FHH}$, which was confirmed by the genetic analysis. However, a few patients were misinterpreted for PHPT and, therefore, underwent surgery subsequently. Due to the persistently elevated postoperative calcium levels, these patients were subjected to genetic analysis and consequently diagnosed with FHH. Only patients with genetically proven FHH1 were eligible for the retrospective analysis.

All patients gave their written informed consent. The data were prospectively documented between 2008 and 2019 and retrospectively analyzed. The study was conducted in accordance with the Declaration of Helsinki (as revised in 2013). The Ethics Committee of the Medical University of Vienna approved the study protocol (No. 1641/2012).

\section{Biochemical analyses}

The following parameters were measured in detail: albumin-corrected serum $\mathrm{Ca}$, intact $\mathrm{PTH}$, total 25 -hydroxycholecalciferol [25(OH)D] and 1,25-dihydroxycholecalciferol [1,25(OH)2D], 24hU CE and $24 \mathrm{hU}$ creatinine excretion. Additionally, CCCR was calculated $[\mathrm{CCCR}=(24 \mathrm{hU} \mathrm{CE} /$ plasma Ca, total $) /(24 \mathrm{hU}$ creatinine excretion/plasma creatinine)] $(4,11)$.

Intact PTH was analyzed on an Elecsys 1010 Autoanalyzer (Roche, Mannheim, Germany). 25(OH)D was evaluated with a COBAS E411 analyzer (Roche, Germany) 
using the chemiluminescence immunoassay "Liaison 25 OH Vitamin D TOTAL assay" (DiaSorin, Saluggia, Italy) and the Elecsys $25 \mathrm{OH}$ assay (Roche, Germany). $1,25(\mathrm{OH}) \mathrm{D}$ was assessed manually via chromatography and radioimmunosorbent assay (DiaSorin, Italy). All other parameters were analyzed using a chemical autoanalyzer (Olympus, Hamburg, Germany). The patients collected their $24 \mathrm{~h}$ urine in appropriate receptacles.

\section{CCCR and CE}

Based on the current literature, CCCR and CE are suitable screening tests to adequately detect potential FHH (4). Taking the general cut-off points in consideration, CCCR values below 0.01 indicate $\mathrm{FHH}$, values from 0.01 to 0.02 are unspecific and therefore categorized in the gray area and values above 0.02 indicate PHPT. The cut-off points for $24 \mathrm{hU}$ CE were determined as $<2.5 \mathrm{mmol} / 24 \mathrm{~h}$ indicative for $\mathrm{FHH}, 2.5-7.5 \mathrm{mmol} / 24 \mathrm{~h}$ standard values and $>7.5 \mathrm{mmol} / 24 \mathrm{~h}$ indicative for PHPT.

Furthermore, interfering factors, such as comorbidities, fasting period and medication (thiazide diuretics), were taken in consideration when assessing CCCR and 24hU CE.

\section{Symptoms}

Whereas FHH is asymptomatic in most cases, PHPT often presents with minimal to severe symptoms. The disorder is interpreted as symptomatic if patients show a classical course with impairment of the kidney, bone or gastrointestinal tract, kidney stones, osteopenia or osteoporosis, chronic gastroenteritis, symptoms of cardiovascular disease (i.e., arterial hypertension) or hypercalcemic syndrome (i.e., fatigue).

\section{Type of surgery}

Cervical ultrasonography and ${ }^{99 \mathrm{~m}} \mathrm{Tc}$-sestamibi scintigraphy were conducted prior to surgery to localize the enlarged parathyroid gland(s). Depending on the result, open minimally invasive parathyroidectomy (OMIP) or bilateral neck exploration (BNE) were performed subsequently (12). Quick PTH monitoring was used intraoperatively to confirm complete excision of hyperfunctioning tissue (13).

Postoperative assessments of albumin-corrected serum $\mathrm{Ca}$, intact $\mathrm{PTH}$, creatinine, 25(OH)D and 24hU CE were conducted on days 1, 4 and 7; follow-up data were collected after 6 weeks, 6 and 12 months.

\section{CaSR genotyping}

Written informed consent was obtained from all patients for CaSR genotyping. Genomic DNA was isolated from ethylene diamine tetraacetic acid (EDTA)-anticoagulated blood according to standard procedures. Exons 2 to 7 were amplified by polymerase chain reaction and were subjected to Sanger sequencing, as published previously (10). NM_000388.3 was used as the reference sequence. Detected variants were analyzed using Alamut Visual Plus (SophiaGenetics) and classified according to the American College of Medical Genetics and Genomics (ACMG) and ClinVar (14-16).

\section{Statistical analyses}

$T$-test was performed using SPSS Statistics 24.0 software (SPSS Inc., Chicago, IL, USA). The results were considered statistically significant if $\mathrm{P}<0.05$.

\section{Results}

A total of 14 patients [female: $n=9(64.3 \%)$, male: $n=5$ $(35.7 \%)$, median age: 50 years; range, 2 to 77 years], initially referred for PHPT by the endocrinologist or the GP to our institution (Medical University of Vienna) for further evaluation and potential treatment, were included in the study. FHH1 was suspected initially in 8/14 (57.1\%) cases (elevated serum $\mathrm{Ca}$ and normal/slightly increased intact PTH and/or CCCR $<0.01$ and/or low $24 \mathrm{hU}$ CE), confirmed by the following genetic analysis. PHPT was assumed in 6/14 (42.9\%) patients (elevated serum Ca and intact PTH and/or CCCR $>0.001$ and/or increased $24 \mathrm{hU}$ CE), who underwent surgery for PHPT. However, the persistent postoperative elevated serum Ca levels and symptoms lead to further genetic analysis, which subsequently revealed FHH1 (Figure 1).

Table 1 shows the baseline parameters of albumincorrected serum $\mathrm{Ca}$, intact PTH and 24hU CE as well as the calculated CCCR for every patient in this study. Intact PTH was increased $(>65 \mathrm{pg} / \mathrm{mL})$ in $6 / 14$ [42.9\% (5/6 interpreted for PHPT)] cases, but in normal range $(15-65 \mathrm{pg} / \mathrm{mL})$ in $8 / 14$ [57.1\% (1/8 interpreted for PHPT)] cases. CCCR $(<0.01)$ indicated $\mathrm{FHH}$ in $8 / 14$ [57.1\% (3/8 wrongly interpreted for PHPT)] patients and $6 / 14$ [42.9\% (3/8 correctly interpreted for PHPT)] patients were in the gray area. In 6/14 [85.7\% (3/6 wrongly interpreted for PHPT)] patients lower levels $(<2.5 \mathrm{mmol} / 24 \mathrm{~h})$ of $24 \mathrm{hU}$ CE were 


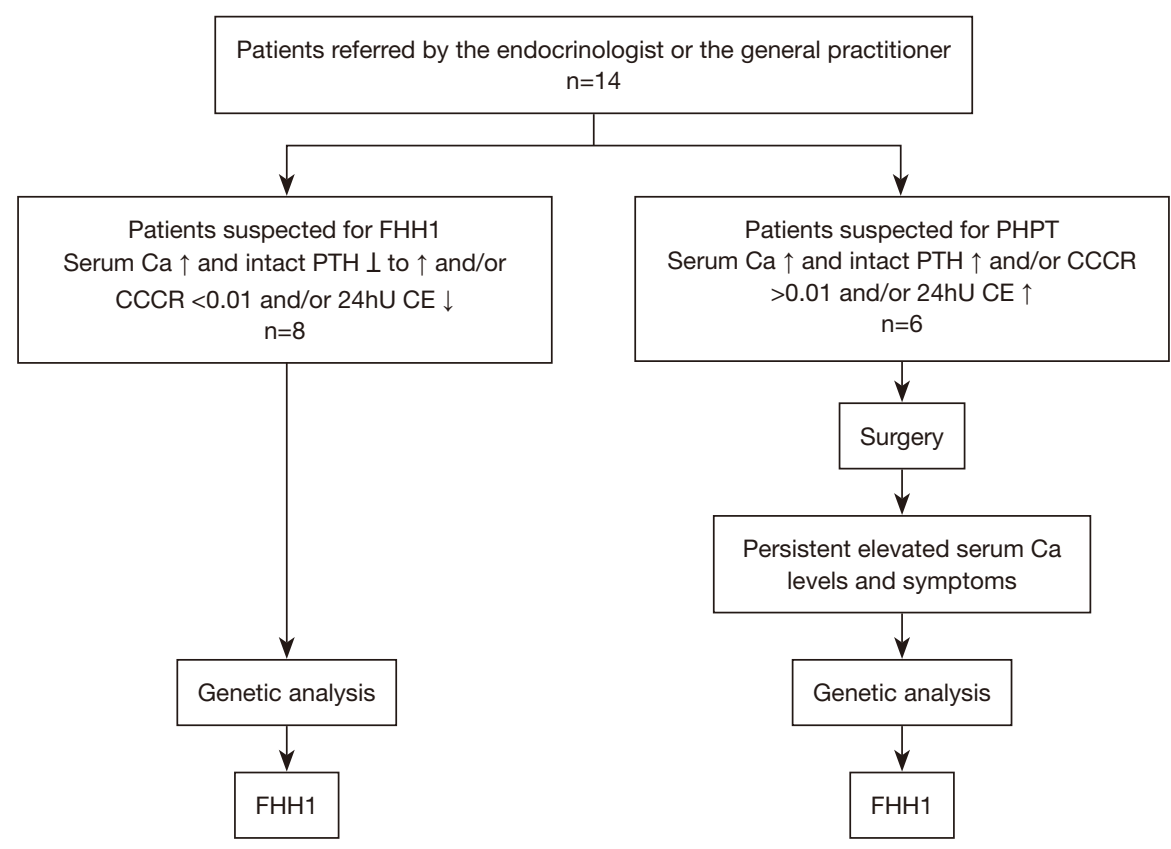

Figure 1 Flow diagram illustrating the screening process of study patients. $\uparrow$, above normal range; $\downarrow$, below normal range; $\perp$, in normal range. FHH1, familial hypocalciuric hypercalcemia; Ca, calcium; PTH, parathyroid hormone; CCCR, calcium/creatinine clearance ratio; 24hU CE, 24-hour urinary calcium excretion; PHPT, primary hyperparathyroidism.

found, indicating FHH. Six of 14 [42.9\% (2/6 interpreted for PHPT)] patients presented normal 24hU CE levels and $2 / 14$ [14.3\% (1/2 correctly interpreted for PHPT)] patients showed increased levels of $24 \mathrm{hU}$ CE.

Eight of $14(57.1 \%)$ patients were clinically asymptomatic and 6/14 (42.9\%) patients showed classical symptoms of PHPT. None of the patients presented any relevant comorbidity or was fasting at the time of analysis. Patients stopped taking thiazide diuretics at least three weeks prior to the assessment of CCCR and $24 \mathrm{hU}$ CE. The patient characteristics are shown in detail in Table 1.

\section{CaSR genotyping}

Analyses were performed in patients with biochemical results suspicious for $\mathrm{FHH} 1$ and persisting disease after undergoing surgery for suspected PHPT. Genetic analysis revealed heterozygous variants (mutations) in different exons: c.1801A>C p.(Lys601Gln) (3 patients), c.1278delC p.(Ile427LeufsX35), c.1096G>T p.(Gly366*), c.1631G>A p.(Arg544Gln), c.668T>C p.(Ile223Thr) (3 patients), c.2282T >A p.(Ile761Asn), c.1636T >A p.(Cys546Ser), c. $212 \mathrm{~T}>\mathrm{G}$ p. $($ Leu71*), c. $1740 \mathrm{~T}>\mathrm{A}$ p.(Ser580Arg), and c.554G>A p.(Arg185Gln) (17). Notably, 9/10 CaSR gene mutations have not yet been reported in the literature or in the CaSR database (www.lovd.nl, www.casrdb.mcgill.ca). Classification of detected CaSR variants and a schematic representation of CaSR gene structure are shown in Table 2 and Figure 2.

\section{Surgery}

Patients, who underwent surgery, were initially biochemically and/or clinically suspected for PHPT and those, who did not undergo surgery, were subjected to genetic analyses due to suspected FHH1.

The median age of operated $(n=6)$ and not operated patients $(n=8)$ was 29 and 67 years, respectively. No significant difference was found between the groups (operated versus not operated) regarding age. We observed a significant difference $(\mathrm{P}=0.034)$ between the groups regarding $25(\mathrm{OH}) \mathrm{D}$, but not for serum $\mathrm{Ca}, \mathrm{PTH}$, $1,25(\mathrm{OH}) 2 \mathrm{D}$, creatinine, $24 \mathrm{hU}$ CE or CCCR. The data are shown in Table 3.

Six of $14(42.9 \%)$ patients underwent surgery for suspected PHPT. At least one enlarged parathyroid gland was removed during the intervention. OMIP was conducted in 1/14 (7.1\%) cases and BNE in 5/14 (35.7\%) cases (Table 4). In 2/14 $(14.3 \%)$ cases, a conversion of primary operation technique to $\mathrm{BNE}$ was necessary due to multifocal disease or incorrect 


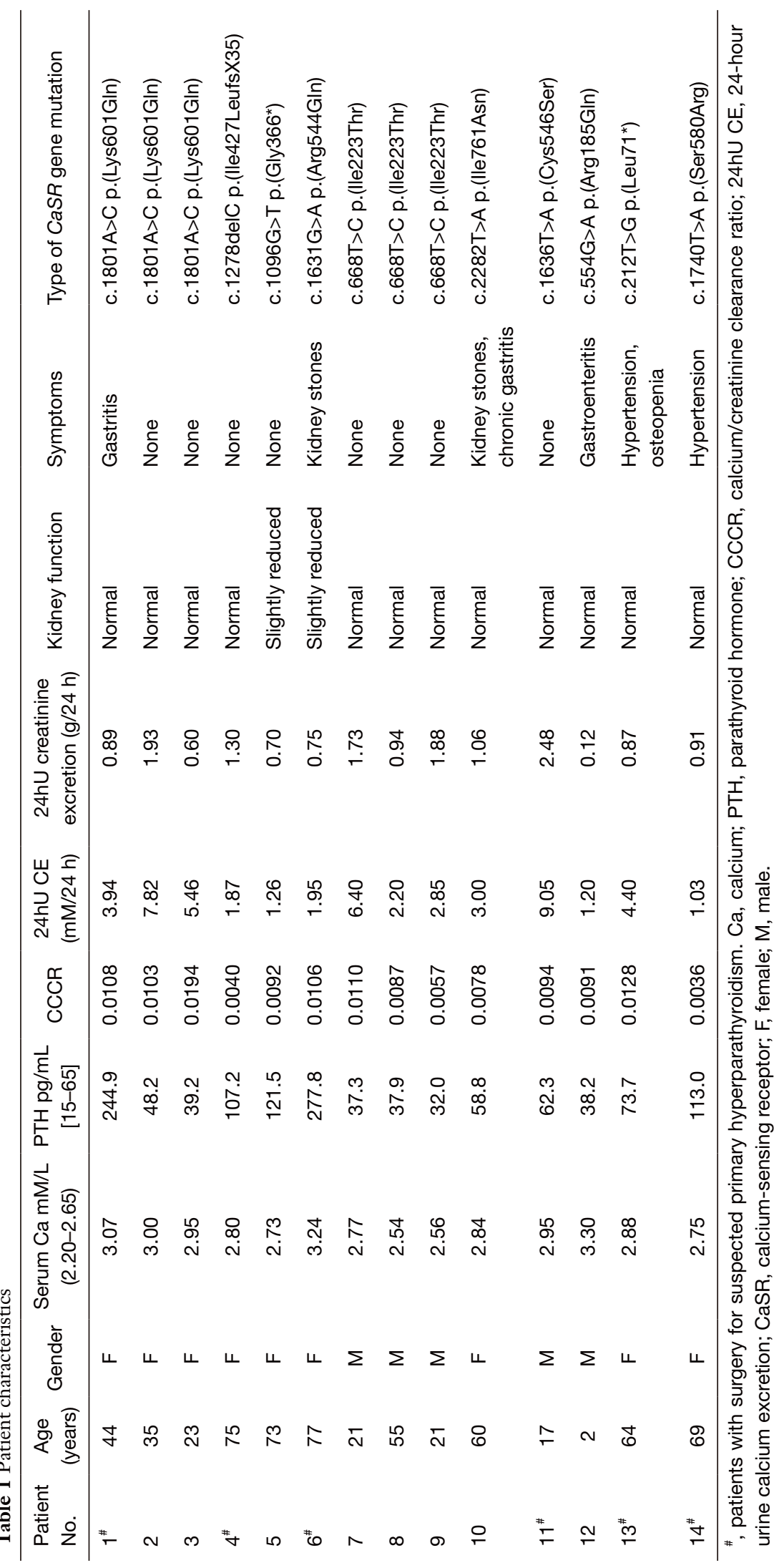


Table 2 Classification of CaSR variants

\begin{tabular}{llllll}
\hline Variant & Protein level & Coding effect & ACMG & SIFT & ClinVar \\
\hline c.1801A $>$ C & p.(Lys601GIn) & Missense & C3 & Deleterious & No annotation \\
c.1278delC & p.(lle427LeufsX35) & Frameshift & C3 & No annotation & No annotation \\
c.1096G $>$ T & p.(Gly366*) & Stop codon, nonsense & C3 & No annotation & No annotation \\
c.1631G $>$ A & p.(Arg544GIn) & Missense & C3 & Tolerated & Conflicting interpretation \\
c.668T>C & p.(lle223Thr) & Missense & C3 & Deleterious & No annotation \\
c.2282T $>$ A & p.(lle761Asn) & Missense & C3 & Deleterious & No annotation \\
c.1636T $>$ A & p.(Cys546Ser) & Missense & C3 & Deleterious & No annotation \\
c.554G $>$ A & p.(Arg185GIn) & Missense & C4 & Deleterious & Pathogenic \\
c.212T $>$ G & p.(Leu71*) & Stop codon, nonsense & C3 & Deleterious & No annotation \\
c.1740T $>$ A & p.(Ser580Arg) & Missense & C3 & Deleterious & No annotation \\
\hline
\end{tabular}

CaSR, calcium-sensing receptor; ACMG, American College of Medical Genetics and Genomics; SIFT, Sorting Intolerant from Tolerant; ClinVar aggregates information about genomic variation and its relationship to human health.

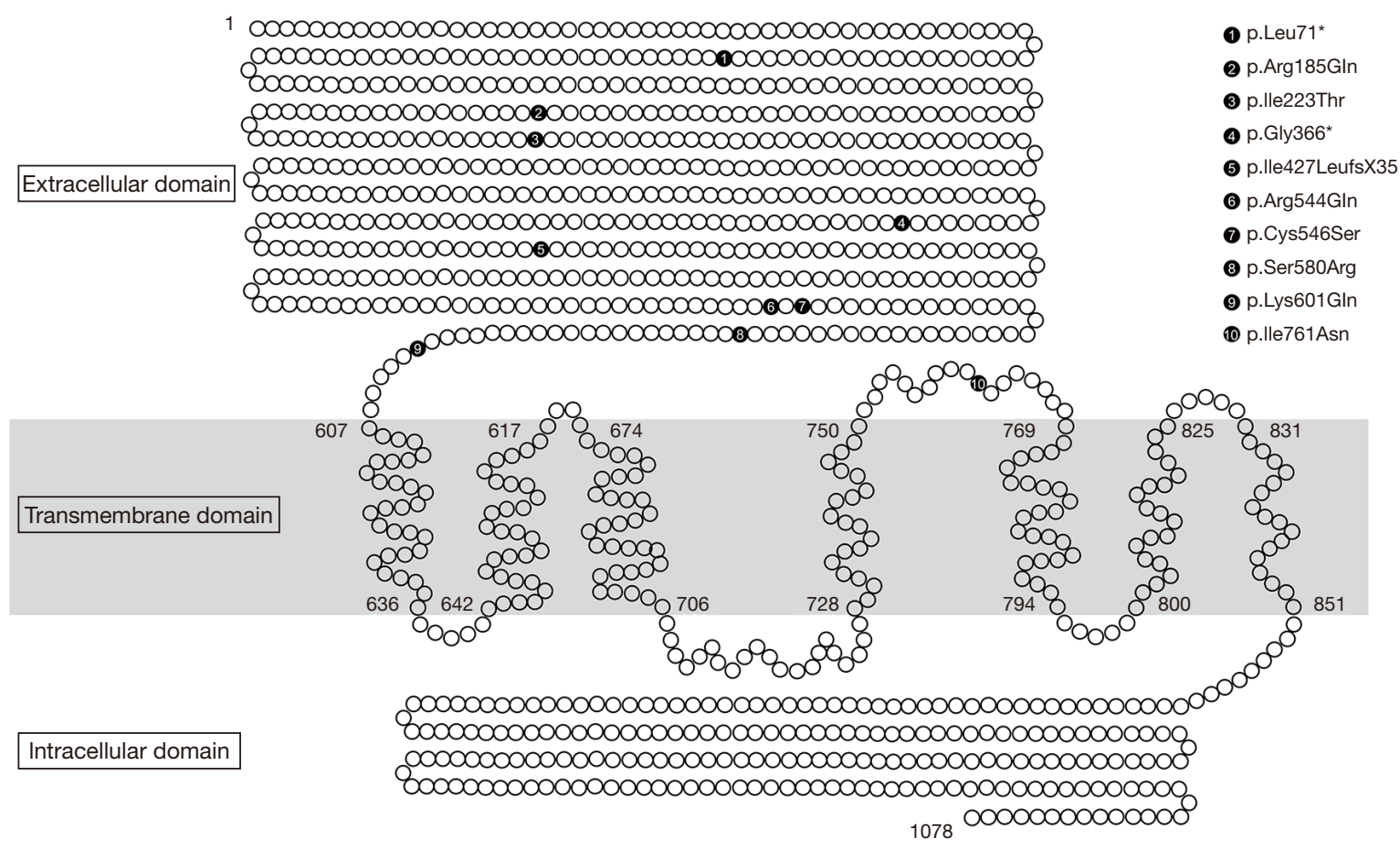

Figure 2 Schematic representation of the human CaSR and location of the mutated amino acids. The CaSR is constituted of 1,078 amino acids and is organized in three structural domains (extracellular, transmembrane and intracellular domains). The amino acids are represented by a white and the mutations by a black circle with the according number. The corresponding mutation is listed in the right upper corner of the figure. 
Table 3 Comparison of initial biochemical parameters of operated $v s$. not operated patients

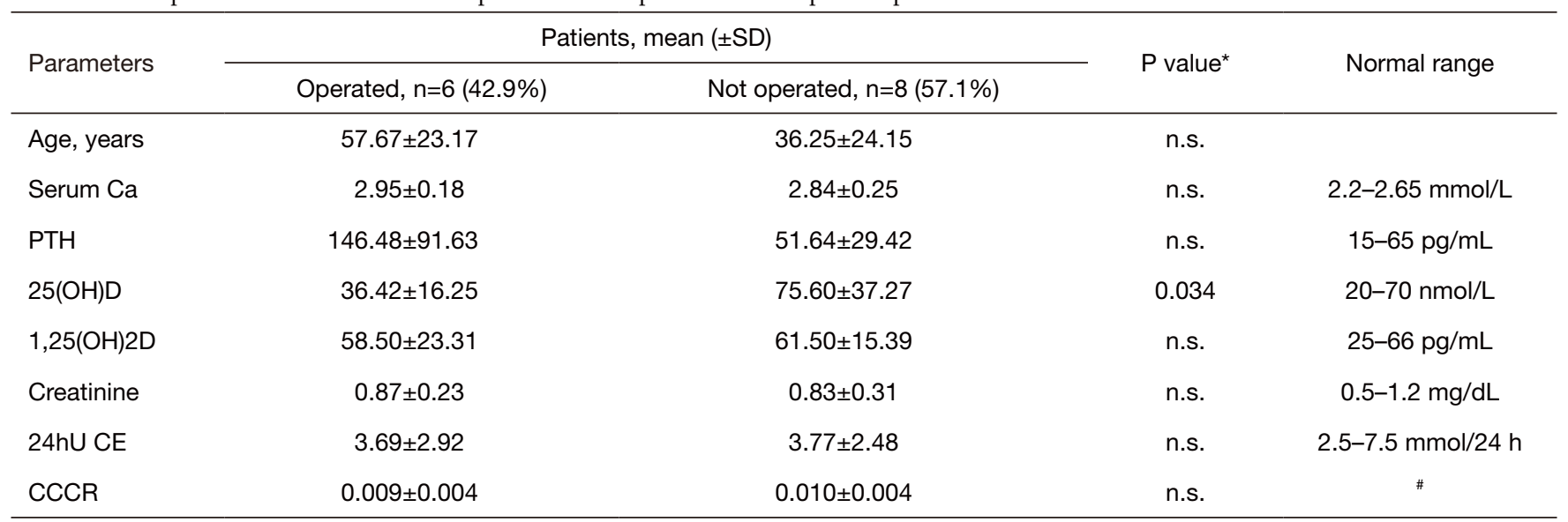

*, reported $\mathrm{P}$ values are computed by unpaired $t$-test; ", calcium/creatinine clearance ratio: <0.01 familial hypocalciuric hypercalcemia, 0.01-0.02 gray area. Ca, calcium; PTH, parathyroid hormone; 25(OH)D, 25-hydroxycholecalciferol; 1,25(OH)2D, 1, 25-dihydroxycholecalciferol; 24hU CE, 24-hour urinary calcium excretion; CCCR, calcium/creatinine clearance ratio; n.s., not significant.

Table 4 Postoperative findings in patients having undergone surgery for suspected PHPT

\begin{tabular}{|c|c|c|c|c|c|c|c|}
\hline $\begin{array}{l}\text { Patient } \\
\text { No. }\end{array}$ & $\begin{array}{c}\text { Age } \\
\text { (years) }\end{array}$ & Gender & Symptoms & $\begin{array}{l}\text { Biochemical } \\
\text { analysis }\end{array}$ & Surgery & Histology & Type of CaSR gene mutation \\
\hline 1 & 44 & $\mathrm{~F}$ & Gastritis & $\mathrm{Ca} \uparrow, \mathrm{PTH} \perp$ & BNE & Normal tissue & c. $1801 \mathrm{~A}>\mathrm{C}$ p.(Lys601GIn) \\
\hline 6 & 77 & $\mathrm{~F}$ & $\begin{array}{l}\text { Kidney stones, reduced } \\
\text { kidney function }\end{array}$ & $\mathrm{Ca} \uparrow, \mathrm{PTH} \perp$ & BNE & Hyperplasia & c. $1631 \mathrm{G}>$ A p. (Arg544GIn) \\
\hline 13 & 64 & $\mathrm{~F}$ & Hypertension, osteopenia & $\mathrm{Ca} \uparrow, \mathrm{PTH} \perp$ & MIP & Adenoma & c.212T>G p. $($ Leu71*) \\
\hline 14 & 69 & $\mathrm{~F}$ & Hypertension & $\mathrm{Ca} \perp, \mathrm{PTH} \perp$ & BNE & Adenoma & c. $1740 T>A$ p.(Ser580Arg) \\
\hline
\end{tabular}

$\uparrow$, above normal range; $\perp$, in normal range. PHPT, primary hyperparathyroidism; CaSR, calcium-sensing receptor; F, female; M, male; Ca, calcium; PTH, parathyroid hormone; BNE, bilateral neck exploration; MIP, minimally invasive parathyroidectomy.

localization diagnostics of an enlarged parathyroid gland. Overall, 3/14 (21.4\%) patients received simultaneous thyroid surgery.

The intraoperative PTH decline was sufficient according to the used criterion (13), and PTH levels were in the normal range by the end of surgery. All patients underwent their interventions without complications and were discharged a few days later. Interestingly, the followup examinations of five patients revealed elevated $\mathrm{Ca}$, but (high) normal PTH levels, and only one patient presented both parameters in the (high) normal range. Unfortunately, clinical symptoms were still present in patients who had undergone parathyroid surgery.

Recurrent surgery was necessary in a single case:
Preoperative multiplexed ion beam imaging and ultrasonography showed positive technetium $\left({ }^{99 \mathrm{~m}} \mathrm{Tc}\right)$ sestamibi intake on the upper left side and a goiter in the thyroid gland. The medical history revealed depression and high blood pressure. An OMIP procedure was performed without complications and an enlarged parathyroid gland was removed. A steady decrease in PTH concentration levels was monitored thereafter. However, on the second and third postoperative days, serum Ca levels increased above the normal range together with a (high) normal PTH level. Initially, the biochemical results had indicated persistent PHPT, which is why recurrent surgery was conducted. During the second operation, the parathyroid gland on the lower left side and the right thyroid gland 
were removed. The histology result revealed an adenoma of the parathyroid gland and a nodular goiter.

\section{Histopathological results}

Histopathological examinations of the removed parathyroid glands revealed adenoma $(n=3)$, suspected hyperplasia $(n=2)$ and normal parathyroid tissue $(\mathrm{n}=1)$, respectively. The details are given in Table 4.

\section{Discussion}

FHH1 is an autosomal dominant disorder caused by pathogenic variants (inactivating mutations) in the CaSR gene and is biochemically characterized by generally asymptomatic hypercalcemia. The differentiation between FHH and PHPT is important for accurate prognosis and correct treatment $(3,4)$, as surgery can be curative in PHPT, but most likely ineffective in FHH.

We report of 14 patients, initially assumed for PHPT. Based on CaSR genotyping, patients were assumed to suffer from FHH1, carrying novel heterozygous variants in the CaSR. Even though every patient is diagnostically clarified externally by the referring GP and endocrinologist prior to the first consultation at our institution, a mandatory, thorough re-checkup (biochemical analysis including CCCR and CE assessment) is conducted for quality assurance. Surprisingly, 8/14 (57.1\%) patients presented a typical biochemical image of $\mathrm{FHH}$, which was confirmed by the following genetic analysis. However, 6/14 (42.9\%) patients were misinterpreted for PHPT and therefore underwent surgery. In the postoperative course, however, these patients showed persisting elevated serum Ca levels and clinical symptoms, leading to further genetic analysis, which suggested FHH1. Interestingly, the pathohistological examination of the specimen showed parathyroid adenomas and hyperplasia.

CCCR, the relation between urinary $\mathrm{Ca}$ clearance and creatinine clearance, is most frequently used to discriminate FHH from PHPT (18). According to the literature, $>80 \%$ of patients with FHH present a CCCR of $<0.01(2,19-21)$. In our study, CCCR indicated FHH in only 8/14 (57.1\%) cases sufficiently. In contrast, 6/14 (42.9\%) patients showed a CCCR $>0.01$, suggesting PHPT. Additionally, we assessed $24 \mathrm{~h}$ renal CE, which is also commonly used as a screening test for $\mathrm{FHH}$ (4). Lower $24 \mathrm{hU}$ CE $(<2.5 \mathrm{mmol} / 24 \mathrm{~h})$ most likely indicates $\mathrm{FHH}$ disorder. In our study population, less than half of the patients $(n=6,42.9 \%)$ showed decreased levels of $24 \mathrm{hU}$ CE. Notably, in two cases (14.3\%), we even measured increased $24 \mathrm{hU}$ CE $(>7.5 \mathrm{mmol} / 24 \mathrm{~h})$, which is highly suggestive of PHPT.

In 2018, Bertocchio et al. presented an unsupervised risk equation (Pro-FHH) indicating PHPT (22). The authors concluded that Pro-FHH (100\% specificity and 100\% positive predictive value) is more effective than $24 \mathrm{~h}$-CCCR (96.8\% specificity and $90 \%$ positive predictive value) in predicting whether a patient had PHPT. Importantly, Pro$\mathrm{FHH}$ is easily calculated as it requires only a measure of calcium, creatinine (in blood and urine), PTH and serum osteocalcin concentrations. However, as stated by the authors, Pro-FHH's weakness is its development based on a retrospective design. Furthermore, Bertocchio et al. included only patients with normal PTH level in their study. In our study, $5 / 6$ patients showed elevated $(>73 \mathrm{pg} / \mathrm{mL})$ and $1 / 6$ patients showed high-normal $(62 \mathrm{pg} / \mathrm{mL})$ PTH concentrations prior to surgery. The effectiveness of ProFHH needs to be investigated in patients with elevated PTH concentration levels. Therefore, a prospective trial is necessary. However, till new data and findings are available, perhaps a combination of diagnostic tools, such as CCCR, $24 \mathrm{hU}$ CE and Pro-FHH, would likely support the screening process.

PHPT and FHH have similar biochemical featureselevated serum $\mathrm{Ca}$ and PTH levels-which makes the distinction very difficult. Furthermore, the differentiation is impeded by an overlap of diagnostic criteria: Patients carrying inactivating mutations in the CaSR gene, which is indicative of FHH1, can also have PHPT with autonomously hypersecreting parathyroid adenomas or hyperplasia. In 1998, Farnebo et al. reported on the relationship between CaSR downregulation and parathyroid hyperplasia, although without fully understanding the precise nature of this association. The authors also described decreased CaSR expression in parathyroid adenomas (23).

Concerning germ line variants, it was only recently that investigators presented data on heterozygous missense mutations in the CaSR gene, which is typical of FHH1, in patients with biochemical and histological findings consistent with PHPT $(1,24)$. Frank-Raue et al. reported on a coexistence of PHPT and CaSR mutations in patients who presented hypercalcemia suggestive of PHPT (1). Another study group, Guarnieri et al., analyzed 165 patients with PHPT and found one case $(0.6 \%)$ with a pathogenic CaSR variant (mutation) (24).

In the present study, and alongside other common benign variants, nine different (heterozygous) variants were 
detected which included nucleotide substitutions that would result in a frameshift, stop codons [e.g., p.(Ile427LeufsX35); p.(Leu71*); p.(Gly366*)] or amino acid substitutions and could thus be causative of FHH1. It is well known that most patients are carriers of so called "private mutations" meaning that those variants are usually not described in the literature and functional assays concerning CaSR-receptor function are not available. This circumstance results in classification of most of the variants as C3 (uncertain significance, according to ACMG), although the observed types of coding effects (frameshift, stop codon) as well as SIFT (sorting intolerant from tolerant) analysis would indicate a pathogenic nature for most of the variants. For p.(Arg544Gln), however, reports are conflicting as to whether this variant is pathogenic or likely benign also resulting in classification of the variant as $\mathrm{C} 3$.

We assume that the above-detected variants [possibly with the exception of the p.(Arg544Gln) variant] lead to FHH1 by functional impairment of the CaSR. Even if coexistent PHPT is cured due to surgery of the respective adenoma, the functional impairment of the CaSR remains.

In 2011, Frank-Raue et al. analyzed the biochemical parameters and CaSR gene alterations of 139 patients presenting with hypercalcemia and suspected of suffering from PHPT. Pathogenic CaSR variants were found in eight patients. Four of these patients underwent surgery for enlarged parathyroids, subsequently revealing single adenomas in the histology results. Based on their findings, the authors concluded that PHPT and FHH1 may coexist in some patients and that precisely these patients would benefit from parathyroid surgery (1). Another study, conducted by Szabo et al. in 2002, comes to a similar conclusion (25): twelve family members with proven FHH, hypercalcemia and elevated serum PTH levels underwent parathyroidectomy. The authors concluded that a resection down to a fraction of a normal-sized gland (10 to $20 \mathrm{mg}$ remnants) would lead to postoperative normocalcemia and less radical procedures to persistent hypercalcemia. Interestingly, CCCR was raised above the diagnostic level of $\mathrm{FHH}(0.01)$ in $70 \%$ of the affected family members. In our study, 6/14 (42.9\%) patients underwent surgery for suspected PHPT. Five of 14 (35.8\%) patients preoperatively presented a "classical PHPT" biochemical pictureelevated PTH and serum Ca levels-and showed few to no symptoms prior to surgery. One of $14(7.1 \%)$ patients demonstrated increased Ca levels, but (high) normal PTH levels. Initially, all but one patient were discharged in a condition of normocalcemia. The histopathological results described adenoma and/or hyperplasia in 5/6 (83.3\%) patients, indicating PHPT. However, in the followup period, removal of a single or multiple parathyroid adenomas resulted in persistently elevated serum $\mathrm{Ca}$, but normalized PTH levels in 5/6 (83.3\%) patients. Only $1 / 6$ (16.7\%) patients showed normal-range serum $\mathrm{Ca}$ and PTH levels. As a consequence, further genetic analyses were conducted, surprisingly revealing FHH1. Ultimately, 5/6 (83.3\%) patients did not benefit from parathyroid surgery even though a coexistence of FHH and PHPT seemed to exist. In contrast, Frank-Raue et al. documented normalized postoperative serum Ca levels in $75 \%$ of their patients (1).

The postoperative histology results revealed adenoma in $3 / 6(50 \%)$ patients, hyperplasia in $2 / 6(33.3 \%)$ and normal parathyroid tissue in $1 / 6(16.7 \%)$ patients. In the literature, mild parathyroid hyperplasia has been described in the majority of patients with $\mathrm{FHH}$ who undergo parathyroidectomy (26). The biochemical image of FHH is accompanied by age-related growth of the parathyroid glands and transition from diffuse to nodular parathyroid hyperplasia. More severely, the development of sporadic parathyroid tumors often results as a consequence of loss of heterozygosity ( $\mathrm{LOH})$ on several chromosomes. Not long ago, Szabo et al. described that LOH would not occur on specific chromosome loci where the CaSR gene is located. Rather, some point mutation resulting in alteration of the intracellular portion of CaSR may cause sensitivity to secondary genetic hits with increased frequency of allelic loss (27).

\section{Conclusions}

We discovered novel CaSR gene mutations, which have not yet been reported in the literature and which considerably impede differential diagnosis of PHPT and FHH1. Our results show that even though the coincidence of $\mathrm{FHH}$ and pathohistological proven PHPT seems to exist, parathyroid surgery does not seem to benefit patients later on.

\section{Acknowledgments}

Funding: None.

\section{Footnote}

Reporting Checklist: The authors have completed the MDAR reporting checklist. Available at https://gs.amegroups.com/ article/view/10.21037/gs-21-577/rc 
Data Sharing Statement: Available at https://gs.amegroups. com/article/view/10.21037/gs-21-577/dss

Peer Review File: Available at https://gs.amegroups.com/ article/view/10.21037/gs-21-577/prf

Conflicts of Interest: All authors have completed the ICMJE uniform disclosure form (available at https://gs.amegroups. com/article/view/10.21037/gs-21-577/coif). The authors have no conflicts of interest to declare.

Ethical Statement: The authors are accountable for all aspects of the work in ensuring that questions related to the accuracy or integrity of any part of the work are appropriately investigated and resolved. The study was conducted in accordance with the Declaration of Helsinki (as revised in 2013). The study was approved by Ethics Committee of the Medical University of Vienna (No. 1641/2012) and informed consent was taken from all the patients.

Open Access Statement: This is an Open Access article distributed in accordance with the Creative Commons Attribution-NonCommercial-NoDerivs 4.0 International License (CC BY-NC-ND 4.0), which permits the noncommercial replication and distribution of the article with the strict proviso that no changes or edits are made and the original work is properly cited (including links to both the formal publication through the relevant DOI and the license). See: https://creativecommons.org/licenses/by-nc-nd/4.0/.

\section{References}

1. Frank-Raue K, Leidig-Bruckner G, Haag C, et al. Inactivating calcium-sensing receptor mutations in patients with primary hyperparathyroidism. Clin Endocrinol (Oxf) 2011;75:50-5.

2. Eastell R, Brandi ML, Costa AG, et al. Diagnosis of asymptomatic primary hyperparathyroidism: proceedings of the Fourth International Workshop. J Clin Endocrinol Metab 2014;99:3570-9.

3. Hinnie J, Bell E, McKillop E, et al. The prevalence of familial hypocalciuric hypercalcemia. Calcif Tissue Int 2001;68:216-8.

4. Christensen SE, Nissen PH, Vestergaard P, et al. Discriminative power of three indices of renal calcium excretion for the distinction between familial hypocalciuric hypercalcaemia and primary hyperparathyroidism: a follow-up study on methods. Clin Endocrinol (Oxf) 2008;69:713-20.

5. Brown EM, MacLeod RJ. Extracellular calcium sensing and extracellular calcium signaling. Physiol Rev 2001;81:239-97.

6. Pidasheva S, D'Souza-Li L, Canaff L, et al. CASRdb: calcium-sensing receptor locus-specific database for mutations causing familial (benign) hypocalciuric hypercalcemia, neonatal severe hyperparathyroidism, and autosomal dominant hypocalcemia. Hum Mutat 2004;24:107-11.

7. Pollak MR, Brown EM, Chou YH, et al. Mutations in the human $\mathrm{Ca}(2+)$-sensing receptor gene cause familial hypocalciuric hypercalcemia and neonatal severe hyperparathyroidism. Cell 1993;75:1297-303.

8. Brennan SC, Thiem U, Roth S, et al. Calcium sensing receptor signalling in physiology and cancer. Biochim Biophys Acta 2013;1833:1732-44.

9. Díaz-Soto G, Rocher A, García-Rodríguez C, et al. The Calcium-Sensing Receptor in Health and Disease. Int Rev Cell Mol Biol 2016;327:321-69.

10. Wolf P, Krššák M, Winhofer Y, et al. Cardiometabolic phenotyping of patients with familial hypocalcuric hypercalcemia. J Clin Endocrinol Metab 2014;99:E1721-6.

11. Glendenning P. Diagnosis of primary hyperparathyroidism: controversies, practical issues and the need for Australian guidelines. Intern Med J 2003;33:598-603.

12. Prager G, Czerny C, Ofluoglu S, et al. Impact of localization studies on feasibility of minimally invasive parathyroidectomy in an endemic goiter region. J Am Coll Surg 2003;196:541-8.

13. Riss P, Kaczirek K, Heinz G, et al. A "defined baseline" in PTH monitoring increases surgical success in patients with multiple gland disease. Surgery 2007;142:398-404.

14. Ng PC, Henikoff S. SIFT: Predicting amino acid changes that affect protein function. Nucleic Acids Res 2003;31:3812-4.

15. Green RC, Berg JS, Grody WW, et al. ACMG recommendations for reporting of incidental findings in clinical exome and genome sequencing. Genet Med 2013;15:565-74.

16. Richards S, Aziz N, Bale S, et al. Standards and guidelines for the interpretation of sequence variants: a joint consensus recommendation of the American College of Medical Genetics and Genomics and the Association for Molecular Pathology. Genet Med 2015;17:405-24.

17. Hannan FM, Nesbit MA, Zhang C, et al. Identification of 70 calcium-sensing receptor mutations in hyper- and hypo- 
calcaemic patients: evidence for clustering of extracellular domain mutations at calcium-binding sites. Hum Mol Genet 2012;21:2768-78.

18. Riss P, Kammer M, Selberherr A, et al. The influence of thiazide intake on calcium and parathyroid hormone levels in patients with primary hyperparathyroidism. Clin Endocrinol (Oxf) 2016;85:196-201.

19. Marx SJ, Attie MF, Levine MA, et al. The hypocalciuric or benign variant of familial hypercalcemia: clinical and biochemical features in fifteen kindreds. Medicine (Baltimore) 1981;60:397-412.

20. Gunn IR, Wallace JR. Urine calcium and serum ionized calcium, total calcium and parathyroid hormone concentrations in the diagnosis of primary hyperparathyroidism and familial benign hypercalcaemia. Ann Clin Biochem 1992;29:52-8.

21. Pearce SH, Brown EM. Disorders of calcium ion sensing. J Clin Endocrinol Metab 1996;81:2030-5.

22. Bertocchio JP, Tafflet M, Koumakis E, et al. Pro-FHH: A Risk Equation to Facilitate the Diagnosis of ParathyroidRelated Hypercalcemia. J Clin Endocrinol Metab

Cite this article as: Bhangu JS, Baumgartner-Parzer S, Hargitai L, Mazal P, Scheuba C, Riss P. Novel mutations of the calcium-sensing receptor impede differential diagnosis of primary hyperparathyroidism and familial hypocalciuric hypercalcemia. Gland Surg 2022;11(1):12-22. doi: 10.21037/gs21-577
2018;103:2534-42.

23. Farnebo F, Höög A, Sandelin K, et al. Decreased expression of calcium-sensing receptor messenger ribonucleic acids in parathyroid adenomas. Surgery 1998;124:1094-8; discussion 1098-9.

24. Guarnieri V, Canaff L, Yun FH, et al. Calcium-sensing receptor (CASR) mutations in hypercalcemic states: studies from a single endocrine clinic over three years. J Clin Endocrinol Metab 2010;95:1819-29.

25. Szabo E, Hellman P, Lundgren E, et al. Parathyroidectomy in familial hypercalcemia with clinical characteristics of primary hyperparathyroidism and familial hypocalciuric hypercalcemia. Surgery 2002;131:257-63.

26. Thorgeirsson U, Costa J, Marx SJ. The parathyroid glands in familial hypocalciuric hypercalcemia. Hum Pathol 1981;12:229-37.

27. Szabo E, Carling T, Hessman O, et al. Loss of heterozygosity in parathyroid glands of familial hypercalcemia with hypercalciuria and point mutation in calcium receptor. J Clin Endocrinol Metab 2002;87:3961-5. 